\title{
Randomized controlled phase III trial of adjuvant chemoimmunotherapy with activated cytotoxic $T$ cells and dendritic cells from regional lymph nodes of patients with lung cancer
}

\author{
Hideki Kimura $^{1} \mathbb{D} \cdot$ Yukiko Matsui $^{2} \cdot$ Aki Ishikawa $^{3} \cdot$ Takahiro Nakajima $^{3} \cdot$ Toshihiko lizasa $^{2}$
}

Received: 31 October 2017 / Accepted: 28 May 2018 / Published online: 31 May 2018

(c) The Author(s) 2018

\begin{abstract}
Randomized controlled trial of adjuvant chemoimmunotherapy for lung cancer indicated a significant advantage in patients receiving immunotherapy. Herein we report the final results and immunological analysis with a median follow-up of 59.6 months. Patients with post-surgical lung cancer were randomly designated to receive either chemoimmunotherapy (group A, immunotherapy arm) or chemotherapy (group B, control arm). The immunotherapy comprised the adoptive transfer of autologous activated killer T cells and dendritic cells (AKT-DC). The 2- and 5-year overall survival (OS) rates were 96.0 and $69.4 \%$ in group A and 64.7 and $45.1 \%$ in group B, respectively. Multivariate analysis results revealed that the hazard ratio was 0.439 . The 2- and 5-year recurrence-free survival rates were 70.0 and $57.9 \%$ in group A and 43.1 and $31.4 \%$ in group B, respectively. Subgroup analysis for the OS between treatment groups indicated that younger patients $(\leq 55$ years: HR 0.098$)$, males (HR 0.474), patients with adenocarcinoma (HR 0.479), patients with stage III cancer (HR 0.399), and those who did not receive preoperative chemotherapy (HR 0.483) had lower HRs than those in the other groups. Immunological analysis of cell surface markers in regional lymph nodes of subjects receiving immunotherapy indicated that the $\mathrm{CD} 8^{+} / \mathrm{CD} 4^{+} \mathrm{T}$-cell ratio was elevated in survivors. Patients with non-small-cell lung cancer benefited from adoptive cellular immunotherapy as an adjuvant to surgery. Patients with stage III cancer, those with adenocarcinoma, and those not receiving preoperative chemotherapy were good candidates. Lastly, cytotoxic T cells were important for a favorable chemoimmunotherapy outcome.
\end{abstract}

Keywords Adjuvant therapy $\cdot$ Lung cancer $\cdot$ Regional lymph nodes $\cdot$ Cellular immunotherapy $\cdot$ Cytotoxic T cells

\section{Abbreviations}

AKT-DC Activated killer T cells and dendritic cells CDTC Circulating and disseminating tumor cells

Parts of this paper were presented at the 16th World Conference on Lung Cancer, WCLC, of the International Association for the study of Lung Cancer, IASLC, on September 6-9, 2015 in Denver, (Co, USA) [J Thorac Oncol 10:S 179 oral 04.01 Abstract] and at the European Society for Medical Oncology (ESMO 2017) Congress, Madrid Spain, on September 8-12, 2017 [ESMO 2017 1144 Oral presentation].

Hideki Kimura

h.kimura1028@seikeikai-cmc.jp

1 Department of Thoracic Surgery, Saiseikai-Narashino Hospital, Izumi-cho 1-1-1, Narashino, Chiba 275-8580, Japan

2 Department of Thoracic Surgery, Chiba Cancer Center, Chiba, Japan

3 Department of General Thoracic Surgery, Graduate School of Medicine, Chiba University, Chiba, Japan

$\begin{array}{ll}\text { CI } & \text { Confidence interval } \\ \text { HR } & \text { Hazard ratio } \\ \text { OS } & \text { Overall survival } \\ \text { RCT } & \text { Randomized controlled trial } \\ \text { RFS } & \text { Recurrence-free survival }\end{array}$

\section{Introduction}

Progress in diagnostic procedures and surgical technology has considerably improved the prognosis of lung cancer surgery $[1,2]$. In advanced cases, patient outcomes remain poor despite progress in adjuvant chemotherapy [3, 4] and molecular-targeted therapy [5]. Patients with stage IIIB and IV lung cancer and malignant pleural effusion, micrometastasis to mediastinal lymph nodes, or intrapulmonary metastasis are often identified after thoracotomy, shortly recur after surgery, and die early. Previously, we recruited advanced lung cancer patients with poor prognoses who had undergone surgery for improving prognosis by immunotherapy 
in combination with adjuvant chemotherapy or moleculartargeted therapy [6]. We present the results with a median follow-up of 59.6 months and the associated statistical immunological analyses.

\section{Patients and methods}

The patients and methods are described in our previous report [6].

\section{Study design and inclusion criteria}

Patients with post-surgical NSCLC were randomly assigned to receive either adjuvant chemoimmunotherapy (group A, immunotherapy arm) or adjuvant chemotherapy (group B, control arm). Immunotherapy consisted of the adoptive transfer of activated cytotoxic killer $\mathrm{T}$ cells and dendritic cells (AKT-DC) derived from the regional lymph nodes of patients with lung cancer. The patient inclusion criteria of this study were as follows: post-surgical patients, $<76$ years; Eastern Cooperative Oncology Group performance status (PS), 0 or 1; adequate bone marrow, liver, and renal function; histology, primary NSCLC, including combined-type small-cell carcinoma; pathological stage, IB with a tumor size $>5 \mathrm{~cm}$ or with severe vessel invasion and II-IV (TNM staging system version 6). Patients with clinical stage I and II cancer received surgery and were pathologically stratified as group a: stage IB, group b: stage II, group c: stage IIIA, and group d: stage IIIB, IV. Patients with clinical stage IIIA cancer (single station $\mathrm{N} 2$ or T3N1) received two courses of induction chemotherapy and were stratified as group e: stage IIIA and group f: stage IIIB, IV diagnosed after thoracotomy (pathological stages). Patients with stages IIIB or IV cancer and malignant pleural effusion, micrometastasis to mediastinal lymph nodes, or intrapulmonary metastasis identified after thoracotomy were also included. Patients who underwent non-curative resection were included, but those with exploratory thoracotomies or macroscopic residual tumors were excluded from this study.

\section{Chemotherapy}

We used platinum doublet regimens belonging to third-generation drugs as induction and adjuvant chemotherapy. Both groups received four courses of adjuvant chemotherapy after surgery (groups a, b, c, and d). Patients with clinical stage IIIA cancer (groups e and f) received two courses of induction and adjuvant chemotherapy. After the confirmation of recurrence, chemotherapy was resumed and EGFR-mutation-positive patients received EGFR-TKI. Immunotherapy was continued or resumed with the patient's consent in combination with chemotherapy.

\section{Preparation of activated killer T cells and dendritic cells from regional lymph nodes}

The procedure involved in the preparation of AKT-DC has been previously described [6]. One to two grams of tumordraining lymph nodes (TDLN) from intrapulmonary to mediastinal lymph nodes with no metastasis was transferred to a sterile Petri dish and aseptically minced into $1-\mathrm{mm}^{3}$ tissue fragments. The tissue preparation was then suspended in $50 \mathrm{ml}$ Alyse (ALyS505N: Cell Science and Technology Institute, Inc., Sendai, Japan) serum-free lymphocyte medium containing $400 \mathrm{IU} / \mathrm{ml}$ human recombinant interleukin 2 , transferred to a $75-\mathrm{cm}^{2}$ culture flask, and incubated at $37{ }^{\circ} \mathrm{C}$ in air containing $5 \% \mathrm{CO}_{2}$. When the TDLN started to release AKT-DC, the tissues and cells were transferred to culture bags. The AKT-DC were separated from the TDLN tissue by filtering through a nylon mesh and were then transferred to another set of bag, split 2-3 times, and harvested. Cells were suspended in the cryoprotective agent CP-1 (Kyokuto Pharm. Co., Tokyo, Japan) with $4 \%$ human albumin and stored at $5-10 \times 10^{9}$ cells/ bag (freeze bag F-100A: NIPRO Osaka, Japan) in $-80{ }^{\circ} \mathrm{C}$ until used. AKT-DC were intravenously infused 1 week after each course of chemotherapy and were then continued once a month for the first 6 months after resection and then every 2 months until 2 years after surgery.

\section{Immunological analysis}

We selected patients who died within 3 years of recurrence $(n=7)$ and compared the cell surface markers with that of other patients $(n=42)$ who were alive at 3 years in group A. Mononuclear cells obtained from regional lymph nodes of the patients after surgery were stained with immunofluorescence and analyzed using flow cytometer before and 1-2 months after the initiation of in vitro culture in IL2 when the cells actively proliferated.

\section{Flow cytometer}

Cells were labeled with human monoclonal anti-CD8, HLADR, CD80, and CD4 antibodies conjugated with fluorescein isothiocyanate (FITC; Becton, Dickinson and Co., NJ, USA) and anti-CD3, B7H1 (PD-L1), CD83, and CD25 antibodies conjugated with phycoerythrin (PE) and counted using a flow cytometer (Cytomics-FC500; Beckman Coulter, CA, USA). 7-Amino-actinomycin D (7AAD) was added to exclude nonviable cells.

\section{Statistical analysis}

The population for analysis was defined as randomly assigned patients eligible before treatment. Overall survival 
(OS) was defined as the time from random assignment to death from any cause. Recurrence-free survival (RFS) was defined as the time from randomization to confirmation of recurrence by the trial cancer board. Survival curves were estimated using the Kaplan-Meier method, and survival rates with $95 \%$ confidence intervals (CIs) were calculated. The survival rates between the treatment arms were compared using the log-rank test, and hazard ratios (HR) were calculated using the Cox proportional hazards model with and without the following covariates: age, sex, histology, stage, and preoperative chemotherapy. The significance level of the two-tailed statistical test was 0.05 . Statistical analyses were performed using the Translational Research Informatics Center (TRI: TRILC1304) and by the Foundation for Biomedical Research and Innovation using SAS (version 9.3; SAS Institute, Cary, NC, USA). Interim analysis was scheduled for 5 years after the initiation of the study regardless of the number of enrolled patients.

\section{Results}

\section{Consort diagram}

As shown in Fig. 1, 453 of 556 patients who underwent surgery for NSCLC between April 2007 and July 2012 were excluded, and the remaining 103 patients were selected for randomization. Of the ineligible patients, 79 were excluded due to age ( $>76$ years), 303 were ineligible due to earlystage tumors. Among 62 patients with stage IIIB and IV cancer, a sufficient number of AKT-DC $\left(>7 \times 10^{9}\right)$ needed for a course of treatment could not be obtained because of immunosuppression in 35 cases (56.5\%), and these patients were excluded from the study. Nine patients were excluded due to hepatitis viral infections or due to refusal to provide an informed consent for immunotherapy.

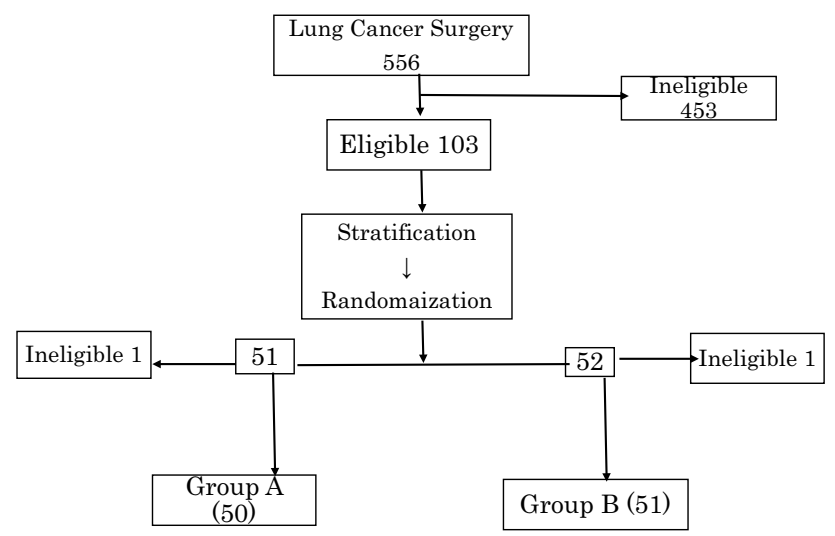

Fig. 1 Consort diagram. Of the 556 patients who underwent surgery between April 2007 and July 2012, 103 were selected for randomization
One patient each from groups A and B was excluded from the study due to a study violation or leukemic conversion of AKT-DC after randomization.

\section{Overall survival}

The difference in OS rates between the treatment arms was noted to be statistically significant (log-rank test, $P=0.0005$ ) and in agreement with our initial findings from 4 years ago [6] (Fig. 2). The 2-, 5-, and 7-year OS rates were 96.0\% (95\% CI 84.9-99.0), 69.4\% (54.4-80.3), and 55.1 (34.3-71.7) in group A and $64.7 \%$ (50.0-76.1), 45.1\% (31.2-58.0), and $38.1 \%(24.6-51.4)$ in group B, respectively. The HRs were 0.451 (95\% CI $0.253-0.807)$ by univariate and 0.439 (0.239-0.807) by multivariate analysis using treatment, age, sex, histology, stage, and preoperative chemotherapy.

\section{Recurrence-free survival}

The 2-, 5-, and 7-year RFS rates were $70.0 \%$ (95\% CI 55.3-80.7), 57.9\% (43.1-70.2), and 47.5\% (29.2-63.8) in group A and $43.1 \%$ (29.4-56.1), 31.4\% (19.3-44.2), and $28.5 \%$ (16.7-41.5) in group B, respectively (Fig. 3). These differences in the RFS rates between the two treatment groups were also noted to be statistically significant (log-rank test, $P=0.0044$ ). The HRs were 0.473 (95\% CI $0.280-0.801)$ by univariate and $0.473(0.275-0.812)$ by multivariate analysis in favor of group A.

\section{OS using Cox proportional hazards model for subgroup analyses and treatment interactions}

The HRs by subgroup analysis of OS between treatment groups that were significantly lower than 1.0 in favor of

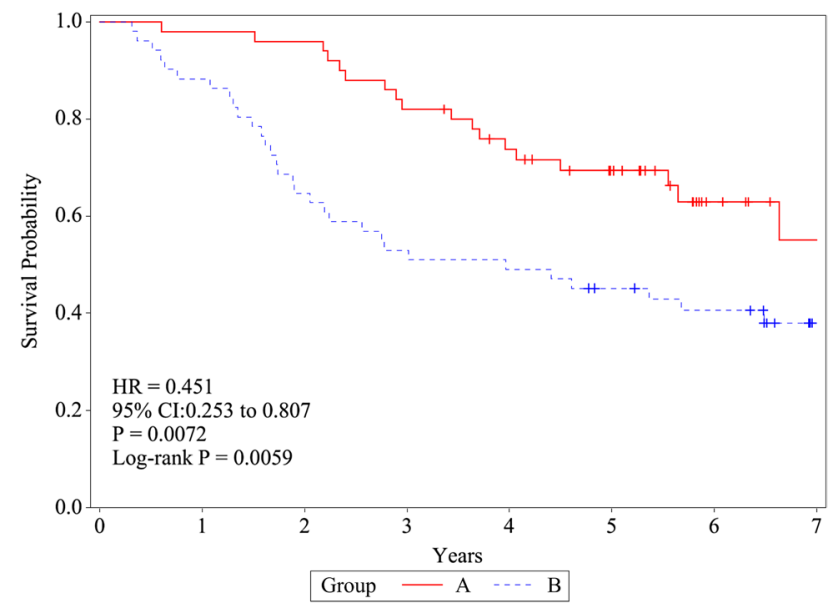

Fig. 2 Overall survival (OS). OS was defined as the time from random assignment to death from any cause and was estimated using the Kaplan-Meier method 


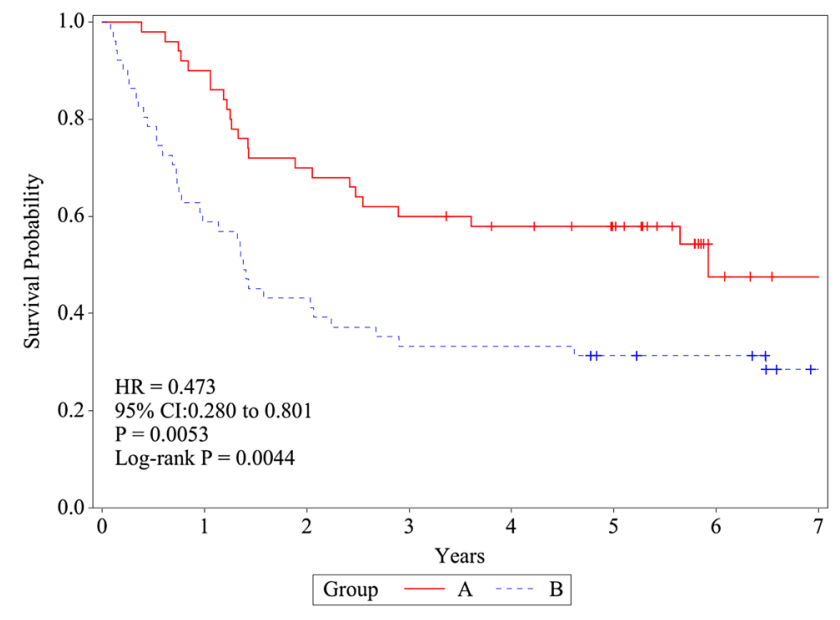

Fig. 3 Recurrence-free survival (RFS). RFS was defined as the time from randomization to confirmation of recurrence by the trial cancer board. RFS was estimated using the Kaplan-Meier method

the immunotherapy arm (Table 1) were as follows: 0.098 (0.011-0.856), age $\leq 55 ; 0.474$ (0.248-0.907), males; 0.479 (0.239-0.959), adenocarcinoma; $0.399(0.194-0.822)$, stage III tumors; and $0.483(0.245-0.951)$, those without preoperative chemotherapy.

\section{RFS using Cox proportional hazards model for subgroup analyses and treatment interactions}

As shown in Table 2, the HRs (95\% CIs) of RFS by subgroup analysis significantly lower than 1.0 in favor of the immunotherapy arm were as follows: $0.058(0.007-0.520)$, age $\leq 55$; 0.216 (0.059-0.791), females; 0.495 (0.269-0.909), adenocarcinoma; 0.446 (0.235-0.845), stage III tumors; and 0.507 (0.271-0.948), patients without preoperative chemotherapy (Table 2).

\section{Cell surface markers and survival}

The $\mathrm{CD} 8^{+} / \mathrm{CD}^{+}{ }^{+} \mathrm{T}$-cell ratio analyzed $1-2$ months after the initiation of in vitro culture was higher in the survivors than in the deceased ( $p=0.013$ : Fig. 4). Additional analyses using cell surface markers for determining the positive percentages of $\mathrm{CD} 8{ }^{+}, \mathrm{CD}^{+}, \mathrm{CD} 80^{+}, \mathrm{CD} 83^{+}, \mathrm{HLA}^{-} \mathrm{DR}^{+}, \mathrm{B} 7 \mathrm{H} 1^{+}$, and T-reg $(\mathrm{CD} 4+\mathrm{CD} 25+)$ cells before and after in vitro culture failed to show significant relationships with survival.

\section{Discussion}

This study is a series of adjuvant immunotherapy trials in patients with post-surgical lung cancer extending over 20 years, starting with Lymphokine activated killer (LAK) cells and continuing with AKT-DC. The first RCT conducted between 1986 and 1992 using LAK cells was reported in the journal Cancer [7]. The results of a phase II study conducted between 1998 and 2004 using AKT-DC obtained from the regional lymph nodes of patients with primary lung cancer predicted a promising outcome for a phase III study using this approach $[8,9]$. The results of this phase III study clearly demonstrate that adoptive cellular immunotherapy benefits patients with lung cancer as an adjuvant to surgery.

Subgroup analysis of OS, comparing the immunotherapy arms using Cox models, indicated that younger patients, male patients, and patients with adenocarcinoma or stage III tumors are good candidates for immunotherapy. The prognosis for stages I and II is better than that for stage III in patients with NSCLC; however, chemoimmunotherapy improved prognosis for stage III more efficiently than it did for stage I and II; this finding was observed in both male and female patients. While the prognosis was better for females than for males, it was significantly improved by immunotherapy in males. Stage IIIB and IV tumors have evolved mechanisms for escaping immune response in the tumor microenvironment [10-13]. The immune system is either inefficient or tolerates the growth of tumors in stages IIIB or IV, which likely leads to ineffective chemoimmunotherapy outcomes in those patients. Lung cancer patients with stage I and II tumors are good candidates for surgery; however, surgery is not indicated in stage IIIA cases due to poor prognosis. If the prognosis of advanced NSCLC can be improved by cell-mediated immunotherapy, surgery may be added to the current treatment modalities for patients with stage IIIA cancer.

The assessment of histological types in this RCT showed that the HR of OS for adenocarcinoma was lower than that for squamous cell carcinoma. Patients with adenocarcinoma were demonstrated to benefit from immunotherapy. It is speculated that metastatic tumors resulting from circulating and disseminating tumor cells (CDTC), the primary residual adenocarcinoma constituents in these patients [14, 15], cannot escape immune surveillance and are eventually eliminated by cell-mediated immunotherapy $[10,16,17]$. Conversely, the residual pattern of squamous cell carcinoma includes residual edges of the resected primary tumor margin, but not CDTC. These residual tumors, like the original tumors, are capable of escaping immune surveillance blocking immune response. We excluded cases with macroscopically residual tumors; however, microscopically residual tumors, such as those with positive bronchial or chest wall margins, were included in the present trial. Squamous cell carcinoma invades the surrounding tissues that remain after resection, induces immunosuppression, and blocks immune responses, and may also prevent effective cell-mediated immunotherapy. 
Table 1 OS using Cox models for subgroup analyses and treatment interactions

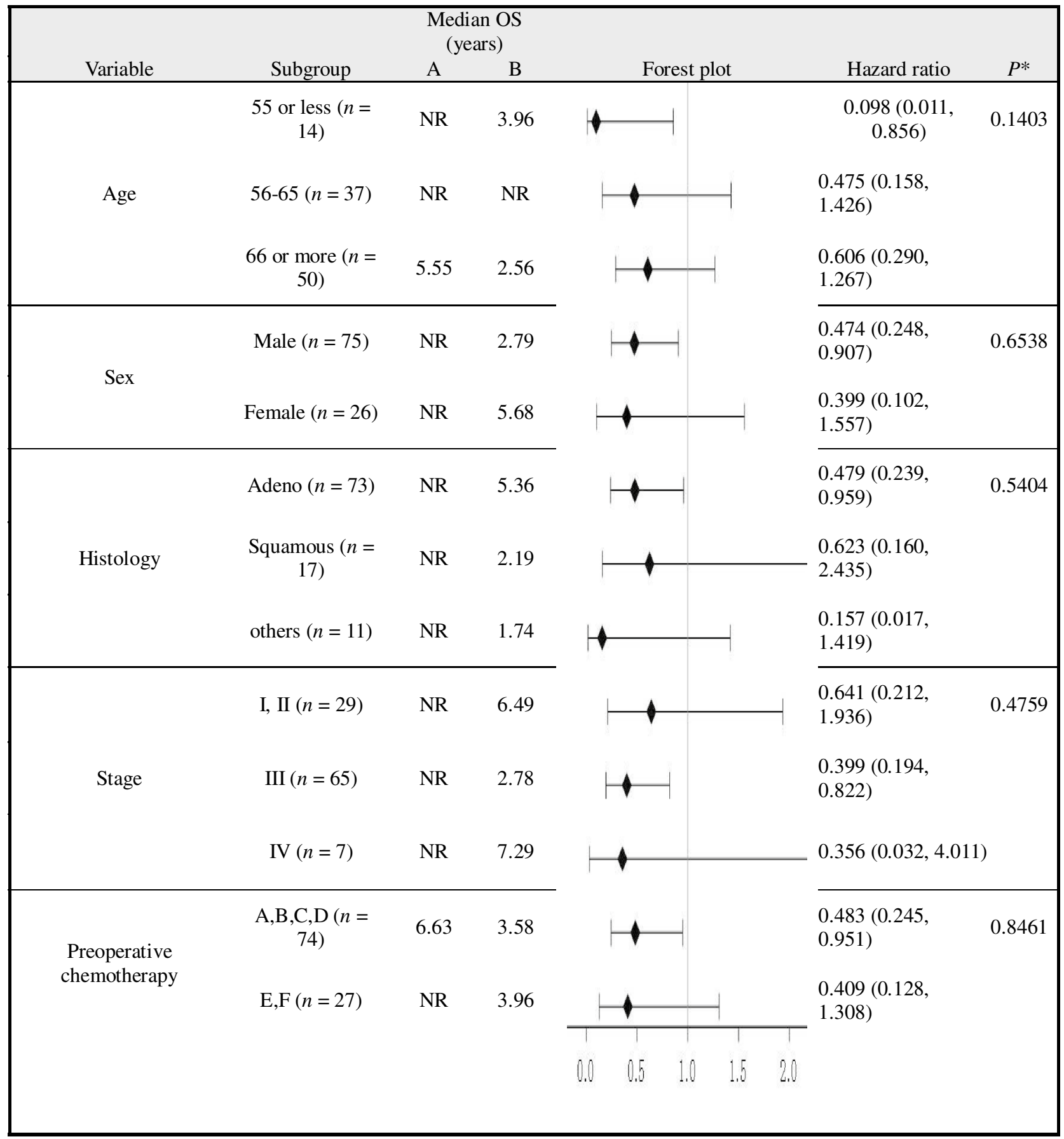

$N R$ not reached to $50 \%$

*P value for treatment interaction

Platinum doublet regimens belonging to the third-generation drugs are used for an induction and adjuvant chemotherapy. Both groups received four courses of adjuvant chemotherapy after surgery (group a, b, c, and d). Stage IIIA patients (group e and f) received two courses of induction chemotherapy before surgery

Patients who did not receive preoperative chemotherapy had lower HRs and benefited from immunotherapy, whereas patients who received preoperative chemotherapy did not significantly benefit from immunotherapy. Specific immune responses may be abrogated by preoperative chemotherapy. Cytotoxic anticancer drugs may negatively affect immune responses in regional lymph nodes, dampening the effect of immunotherapy. 
Table 2 RFS using Cox models for subgroup analyses and treatment interactions

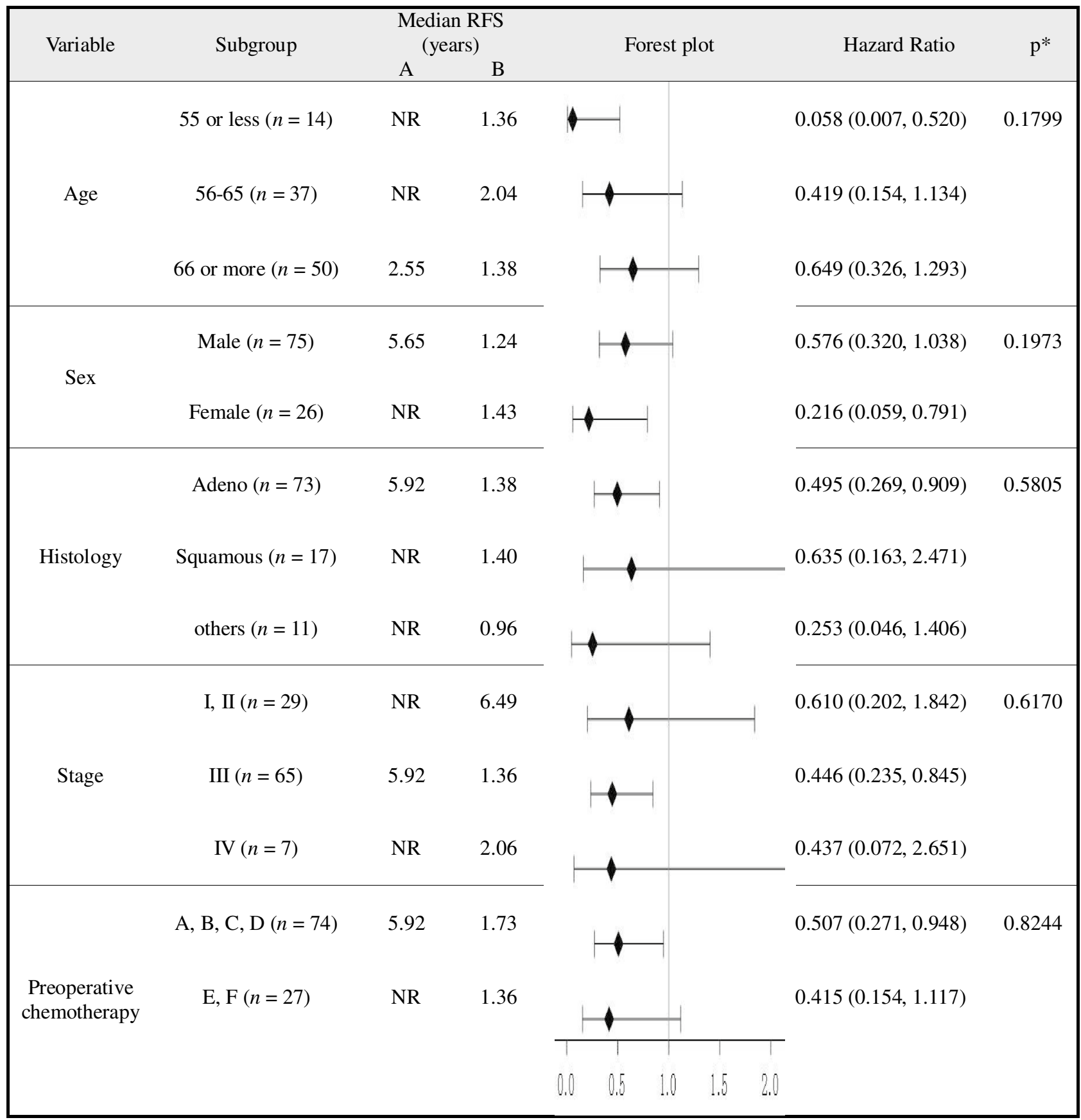

$N R$ not reached to $50 \%$

$* P$ value for treatment interaction

Immunological analysis using cell surface markers of cultured lymphocytes indicated that the $\mathrm{CD} 8^{+} / \mathrm{CD} 4^{+} \mathrm{T}$-cell ratio was elevated in survivors. Analysis using other cell surface markers of lymphocytes before and after in vitro culture failed to show any significant correlation with survival. These results indicated that $\mathrm{CD} 8^{+}$cytotoxic $\mathrm{T}$ cells were more effective than $\mathrm{CD} 4^{+}$helper $\mathrm{T}$ cells in the adjuvant therapy circumstances in this study. The effect of direct cytotoxic killer T cells seems to be more significant than that of indirect support from helper T cells in eliminating CDTC.

Most cancer recurrences result from CDTC, which are clinically undetectable at the time of resection of a primary carcinoma $[14,15]$. The immune response against CDTC released from primary tumors is distinct from that against original tumors regarding immunosuppression, which is induced by several immune escape mechanisms. Original 


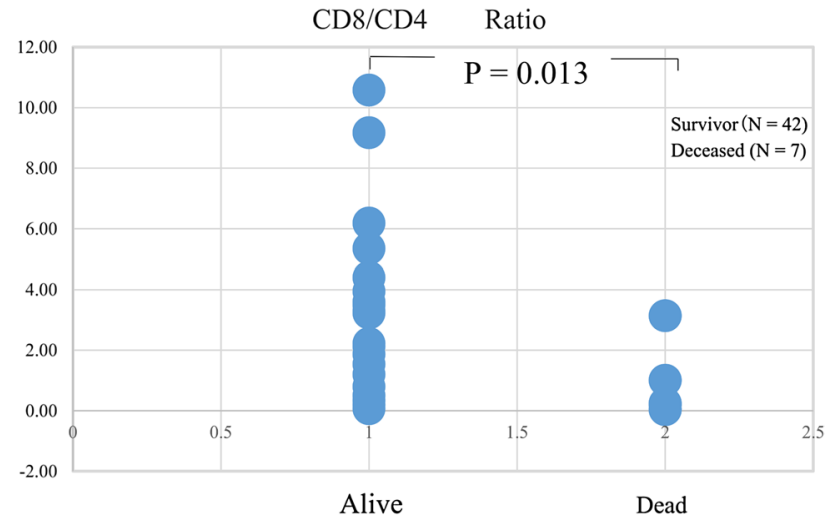

Fig. 4 Cell surface markers and survival. The relationship between cell surface markers and survival was examined, which showed that the $\mathrm{CD} 8^{+} / \mathrm{CD} 4^{+}$ratio was elevated in survivors

tumors are not susceptible to cell-mediated immunotherapy due to several immune escape mechanisms, whereas CDTC may get eliminated by cell-mediated immunotherapy because they can evade neither immune surveillance nor immune response.

The target of immunotherapy in this trial was not the primary lesion, but the undetectable tumor cells remaining after the resection of primary carcinoma of the lung.

The phenotypic diversity of disseminated cells resulting from intra-tumor heterogeneity $[18,19]$ gives rise to clones that are resistant to chemotherapy and prevents tumor cell eradication by chemotherapy. The heterogeneity of tumor cells enables them to escape even from molecular-targeted therapy $[20,21]$. The regional lymph nodes of patients with lung cancer are the organ where the first adaptive immune response against cancer develops [22, 23]. Dendritic cells at the tumor site internalize antigens, migrate to lymph nodes, and induce naive $\mathrm{T}$ cells to become antigen-specific cytotoxic T cells [24]. They act as messengers between the innate and adaptive immune response. From initiation to progression of cancer, tumor cells give rise to various antigens, which are recognized by dendritic cells. Regional lymph nodes represent one of the frontline defense mechanism against cancer to cope with heterogeneous cancer cells. Cell-mediated immunotherapy derived from regional lymph nodes as a source of dendritic cells and cytotoxic $T$ cells may finally eradicate heterogeneous tumor cell clones that disseminate throughout the body, carrying a wide variety of antigens before immunosuppression develops in micrometastases. An important point to consider is whether the sufficient number of AKT-DC can be obtained from the patient for this cell-mediated immunotherapy, as we noticed that AKT-DC could not be obtained in the required quantities in nearly $56 \%$ of the stage IIIB and IV cases.

Even though our results suggest the clinical significance of cell-mediated immunotherapy along with chemotherapy for patients with lung cancer, there are certain limitations of this study. This study was carried out with a relatively small group of patients (only 103 patients) and at a single institution and only in Japan. Also, this was not a blinded study and the included patients were heterogeneous population. A large-scale, double-blind, randomized, multiinstitutional trial is essential for ascertaining the efficacy of the presently described adjuvant cellular immunotherapy procedure and its clinical application. Successful dissemination of skills is required for the culture of regional lymph nodes to successors and this requires experience, time, and financial resources. Close cooperation and collaboration to extend the study protocol nationwide will be immensely beneficial to patients with lung cancer awaiting this cellular immunotherapy.

Acknowledgements The authors are indebted to Mr. CWP Reynolds, associated with Tokyo Medical University, for his editing of this manuscript for its English language content. The authors would like to thank Enago (http://www.enago.jp) for the English language review.

Author contributions Conception and design: HK, TN, TI. Collection and assembly of data: YM, AI. Data analysis and interpretation: HK, TI. Manuscript writing: HK. Final approval of manuscript: all authors.

Funding No relevant funding.

\section{Compliance with ethical standards}

Conflict of interest The authors declare that they have no conflict of interest.

Ethical approval and ethical standards The trial protocol was reviewed and approved by the ethics committee of Chiba Cancer Center and the University Hospital Medical Information Network in Japan (UMIN:CCCI). Patient enrollment and random assignment were performed by Internet Data and Information Center for Medical Research (INDICE 000007525), which is supported by a Japanese government body. This study was conducted in accordance with the ethical principles of the Declaration of Helsinki and the International Conference on Harmonization of Good Clinical Practice guidelines.

Informed consent Informed consent was obtained from all individual participants included in the study.

Open Access This article is distributed under the terms of the Creative Commons Attribution 4.0 International License (http://creativeco mmons.org/licenses/by/4.0/), which permits unrestricted use, distribution, and reproduction in any medium, provided you give appropriate credit to the original author(s) and the source, provide a link to the Creative Commons license, and indicate if changes were made.

\section{References}

1. Puri V, Crabtree TD, Bell JM, Broderick SR, Morgensztern D, Colditz GA, Kreisel D, Krupnick AS, Patterson GA, Meyers BF, Patel A, Robinson CG (2015) Treatment outcomes in stage I lung 
cancer: a comparison of surgery and stereotactic body radiation therapy. J Thorac Oncol 10:1776-1784. https://doi.org/10.1097/ JTO.0000000000000680

2. Khullar OV, Liu Y, Gillespie T, Higgins KA, Ramalingam S, Lipscomb J, Fernandez FG (2015) Survival after sublobar resection versus lobectomy for clinical stage ia lung cancer: an analysis from the national cancer data base. J Thorac Oncol 10:1625-1633. https://doi.org/10.1097/JTO.0000000000000664

3. Pless M, Stupp R, Ris HB, Stahel RA, Weder W, Thierstein S, Gerard MA, Xyrafas A, Früh M, Cathomas R, Zippelius A, Roth A, Bijelovic M, Ochsenbein A, Meier UR, Mamot C, Rauch D, Gautschi O, Betticher DC, Mirimanoff RO, Peters S, SAKK Lung Cancer Project Group (2015) Induction chemoradiation in stage IIIA/N2 non-small cell lung cancer: a phase 3 randomised trial. Lancet 386:1049-1056. https://doi.org/10.1016/S0140 -6736(15)60294-X

4. Arriagada R, Bergman B, Dunant A (2004) International Adjuvant Lung Cancer Trial Collaborative Group. Cisplatin based adjuvant chemotherapy in patients with completely resected NSCLC. N Engl J Med 350:351-360

5. Morgensztern D, Campo MJ, Dahlberg SE, Doebele RC, Garon E, Gerber DE, Goldberg SB, Hammerman PS, Heist RS, Hensing T, Horn L, Ramalingam SS, Rudin CM, Salgia R, Sequist LV, Shaw AT, Simon GR, Somaiah N, Spigel DR, Wrangle J, Johnson D, Herbst RS, Bunn P, Govindan R (2015) Molecularly targeted therapies in non-small cell lung cancer annual update 2014. J Thorac Oncol 10:S1-S63. https://doi.org/10.1097/JTO.000000000000040 5

6. Kimura H, Matsui Y, Ishikawa A, Nakajima T, Yoshino M, Sakairi Y (2015) Randomized controlled phase III trial of adjuvant chemoimmunotherapy with activated killer $T$ cells and dendritic cells in patients with resected primary lung cancer. Cancer Immunol Immunother 64:51-59. https://doi.org/10.1007/s0026 2-014-1613-0

7. Kimura H, Yamaguchi Y (1997) A phase III randomized study of interleukin-2 lymphokine-activated killer cell immunotherapy combined with chemotherapy or radiotherapy after curative or noncurative resection of primary lung carcinoma. Cancer 80:42-49

8. Kimura H, Dobrenkov K, Iida T, Suzuki M, Ando S, Yamamoto N (2005) Tumor-draining lymph nodes of primary lung cancer patients: a potent source of tumor-specific killer cells and dendritic cells. Anticancer Res 25:85-94

9. Kimura H, Iizasa T, Ishikawa A, Shingyouji M, Yoshino M, Kimura M, Inada Y, Matsubayashi K (2008) Prospective phase II study of post-surgical adjuvant chemo-immunotherapy using autologous dendritic cells and activated killer cells from tissue culture of tumor-draining lymph nodes in primary lung cancer patients. Anticancer Res 28:1229-1238

10. Dunn GP, Bruce AT, Ikeda H, Old LJ, Schreiber RD (2002) Cancer immunoediting: from immune-surveillance to tumor escape. Nat Immunol 3:991-998. https://doi.org/10.1038/ni1102-991

11. Whiteside TL (2008) The tumor microenvironment and its role in promoting tumor growth. Oncogene 27:5904-5912. https://doi. org/10.1038/onc.2008.271

12. Becker JC, Andersen MH, Schrama D, Thor Straten P (2013) Immune-suppressive properties of the tumor microenvironment.
Cancer Immunol Immunother 62:1137-1148. https://doi. org/10.1007/s00262-013-1434-6

13. Kerkar SP, Restifo NP (2012) Cellular constituents of immune escape within the tumor microenvironment. Cancer Res 72:31253130. https://doi.org/10.1158/0008-5472.CAN-11-4094

14. O'Flaherty JD, Gray S, Richard D, Fennell D, O'Leary JJ, Blackhall FH, O'Byrne KJ (2012) Circulating tumour cells, their role in metastasis and their clinical utility in lung cancer. Lung Cancer 76:19-25. https://doi.org/10.1016/j.lungcan.2011.10.018

15. Gorges TM, Pantel K (2013) Circulating tumor cells as therapy related biomarkers in cancer patients. Cancer Immunol Immunother 62:931-939. https://doi.org/10.1007/s00262-012-1387-1

16. Kim R, Emi M, Tanabe K (2007) Cancer immunoediting from immune surveillance to immune escape. Immunology 121:1-14. https://doi.org/10.1111/j.1365-2567.2007.02587.x

17. Schreiber RD, Old LJ, Smyth MJ (2011) Cancer immunoediting: integrating immunity's roles in cancer suppression and promotion. Science 331:1565-1570. https://doi.org/10.1126/science.1203486

18. Gerlinger M, Rowan AJ, Horswell S, Math M, Larkin J, Endesfelder D, Gronroos E, Martinez P, Matthews N, Stewart A, Tarpey P, Varela I, Phillimore B, Begum S, McDonald NQ, Butler A, Jones D, Raine K, Latimer C, Santos CR, Nohadani M, Eklund AC, Spencer-Dene B, Clark G, Pickering L, Stamp G, Gore M, Szallasi Z, Downward J, Futreal PA, Swanton C (2012) Intratumor heterogeneity and branched evolution revealed by multiregion sequencing. N Engl J Med 366:883-892. https://doi.org/10.1056/ NEJMoa1113205

19. Marusyk A, Almendro V, Polyak K (2012) Intra-tumour heterogeneity: a looking glass for cancer? Nat Rev Cancer 12:323-334. https://doi.org/10.1038/nrc3261

20. Kuwai T, Nakamura T, Kim SJ, Sasaki T, Kitadai Y, Langley RR, Fan D, Hamilton SR, Fidler IJ (2008) Intratumoral heterogeneity for expression of tyrosine kinase growth factor receptors in human colon cancer surgical specimens and orthotopic tumors. Am J Pathol 172:358-366. https://doi.org/10.2353/ajpath.2008.070625

21. Furnari FB, Cloughesy TF, Cavenee WK, Mischel PS (2015) Heterogeneity of epidermal growth factor receptor signalling networks in glioblastoma. Nat Rev Cancer 15 1:302-310. https:// doi.org/10.1038/nrc3918

22. Maass G, Schmidt W, Berger M, chilcher F, Koszik F, Schneeberger A, Stingl G, Birnstiel ML, Schweighoffer T (1995) Priming of tumor-specific $\mathrm{T}$ cells in the draining lymph nodes after immunization with interleukin 2-secreting tumor cells: three consecutive stages may be required for successful tumor vaccination. Proc Natl Acad Sci USA 92:5540-5544

23. Schweighoffer T, Schmidt W, Buschle M, Birnstiel ML (1996) Depletion of naive $\mathrm{T}$ cells of the peripheral lymph nodes abrogates systemic antitumor protection conferred by IL-2 secreting cancer vaccines. Gene Ther 3:819-824

24. Adema GJ, Hartgers F, Verstraten R, de Vries E, Marland G, Menon S, Foster J, Xu Y, Nooyen P, McClanahan T, Bacon KB, Figdor CG (1997) A dendritic-cell derived C-C chemokine that preferentially attracts naive T cells. Nature 387:713-717. https:// doi.org/10.1038/42716 